УДК $001.18+37.01$

\title{
В.Г. Федотова
}

Типы глобальных сценариев и вектор России ${ }^{1}$

Аннотация:

Возрастающая нелинейность социальных изменений, свойственная рубежу XX-XXI веков, коренным образом видоизменяет механизмы прогнозных сценариев развития. На смену экстраполяционным футурологическим моделям приходят нелинейные, вероятностные прогнозы «проекты», где раскрытие перспектив будущего уже невозможно без учета значимости социальноинженерных замыслов. Приведенная в статье типологизация футурологических сценариев, выявляет сложность объективного видения возможного будущего в фокусе стремительного глобального развития.

Ключевые слова: прогнозирование, футурологические сценарии развития, сценариипроекты, сценарии-тренды, сценарии-идеологии, сценарии-образы.

Об авторе: Федотова Валентина Гавриловна - доктор философских наук, профессор, главный научный сотрудник Института философии РАН, руководитель научного направления «Социальная философия и развитие гражданского общества в России», сектор социальной философии Института философии РАН (Москва), академик РАЕН.

Чем менее определенно будущее, тем больше появляется футурологических работ, прогнозов и предупреждений, попыток уйти от нежелательных исходов, повернуть к лучшему. Большинство прогнозов в XVIII и особенно XIX веках основывалось на признании закономерности, объективного хода истории, естественно-исторических процессов, которые экстраполировались на будущее. Так, А. Смит прогнозировал развитие невидимой руки рынка. Д. Юм писал ему в письме, что хорошо бы, чтобы так же, как в Англии, рынок развился во Франции, и в Германии, но в этих странах капитализм возник позже. Однако естественно-историческая закономерность его распространения в будущем была замечена. Т. Мальтус прогнозировал жизнь человечества в условиях несовпадающего демографического роста и роста продовольствия: человечество не может расти, опережая рост продовольственных ресурсов. По этим, казавшимся объективными, причинам ограничение роста народонаселения виделось ему центральной тенденцией и задачей будущего. К. Маркс раскрыл перспективу будущего как объективно связанную с миссией пролетариата, не имеющего корыстных интересов и стремящегося к освобождению человечества.

\section{Сценарные прогнозы}

$\mathrm{B}$ последней трети XX века прогнозы формируются иначе. Подчеркивается значимость человеческих целей, творческих планов, социально-инженерных замыслов. В лучшем случае речь идет о реализации новых тенденций. Получает распространение слово «проект» в отношении будущего, понятие социальной инженерии.

В XXI веке характер прогнозов меняется. Они становятся вероятностными, нелинейными, имеющими сценарный характер из-за возрастающей нелинейности социальных изменений.

Я различаю: сценарии-образы - некоторое видение, способное воплотиться если не в проект, то в идеологию; сценарии-тренды - выявление объективных тенденций возможного будущего, как правило, мотивированные предпочтением одной из возможных тенденций; сценарии-проекты, в

\footnotetext{
${ }^{1}$ Статья подготовлена при поддержке гранта РФФИ № 12-06-00240 «Концепции внеэкономического капитала как фактор повышения комплексности исследования современной социокультурной динамики».
} 
которых это будущее предлагается конструировать, и сценарии-идеологии, в которых конструирование начинается с выдвижения привлекательных идей. Чаще всего эти типы сценариев комбинируются, создавая переход от сценариев-образов к сценариям-проектам или к сценариямидеологиям, от сценариев-трендов - к сценариям-проектам и т.д. Для того чтобы работать со сценарием, надо понимать, каким из указанных четырех сценариев или комбинацией каких из них он является. Сценарий-образ будит мысль, собирает сторонников и противников, намечает контуры будущего, ориентируясь на эмоциональные предпочтения. Сценарий-тренд призывает увидеть некоторую объективную тенденцию и заставляет одних полагаться на нее, а других делать что-то, что способствует ее осуществлению или замедлению. Он строится как научно обоснованное предположение относительно закономерности развития и в какой-то мере его неизбежной направленности. В этом есть определенное противоречие сценарному подходу: сценарий-тренд утверждает объективность процесса, хотя сценарный подход в целом - множественность сценариев. Сценарий-проект использует проективные возможности человека в обеспечении перехода к желаемому сценарию и его осуществлению, к наращиванию экономического и внеэкономического капитала - человеческого, социального, культурного. Социальный капитал как доверие в обществе имеет особое значение. Сценарии-идеологии мобилизуют общество на решение определенных задач [4, 392-441].

В плане практическом необходимо ориентироваться на сценарии всех четырех типов, чтобы ответить на вопросы: чего мы хотим? возможно ли это объективно? какой проект для этого предлагается? какие альтернативы ему возможны? какая идеология может мобилизовать на решение поставленных задач, чтобы они не просто были инициированы сверху, а вовлекали население?

В каждом сценарии есть объективные предпосылки и субъективные предпочтения, мотивы. Как перспективные, так и неперспективные сценарии всех четырех указанных типов могут реализоваться с разной социальной ценой, а могут и вообще не реализоваться. Сценарные прогнозы возникают в условиях объективной неопределенности ситуации и при наличии разных точек зрения, мотивированных разными образами будущего. Важно не отбрасывать негативный прогноз, а стремиться предотвратить его реализацию и поддержать прогнозы позитивного развития страны. В США платят тем, кто предсказывает риски, и чем более страшные риски предсказываются, тем выше плата. В России платят тем, кто рассказывает о том, что все хорошо и дальше будет еще лучше. Такая услужливость работает на доверие к власти здесь и теперь, но может подорвать его впредь.

\section{Сценарии второй половины $X X-$ начала XXI веков}

После Второй мировой войны были проекты, изменившие существующие тенденции развития. Один из них был научным проектом японских ученых, отказывающихся от либерализма послевоенной американской модели для Японии и объявивших переход к идеям сохранения коллективной продуктивности в 1950-е гг. Вторым - немецкий проект Л. Эрхарда, построенный на концепции ордолиберализма и практически-политических соображениях.

В 1967 г. Дж. Гэлбрейт издал книгу «Новое индустриальное общество», где выдвигает концепцию нового индустриализма, в функционировании которого играет роль государство, образуя техноструктуру.

В 1982 г. Дж. Несбит дал самый потрясающий прогноз как по форме, так и по содержанию. Это - десять позиций, обозначающих доминирующие тенденции и их альтернативы: индустриальное общество - информационное общество; развитые технологии - высокие технологии с уравновешивающимся человеческим ответом; национальная экономика - мировая экономика; кратковременность - долговременность; централизация - децентрализация; институциональная помощь - самопомощь; представительная демократия - демократия участия; иерархия - сеть; или/или - многообразный выбор.

Большую роль сыграл труд П. Кеннеди (1993), прогнозировавший и теоретически обосновывающий связь между экономическим развитием и модернизацией, показавшим одновременно оборотную сторону этого процесса.

В начале 1990-х после распада СССР американский профессор, директор Центра прогнозирования будущего Гарвардского университета С. Хантингтон выдвинул прогноз 
возможного столкновения цивилизаций. Поскольку конфликт холодной войны казался исчерпанным, люди отпрянули к своим этнокультурным истокам, составляя цивилизации как группы близкородственных народов, которые отличались друг от друга настолько, что могли вступить в столкновение. Хантингтон не стремился к конфликту, он его предупреждал. В 1993 г. им была представлена карта раскола Украины, соответствующая сегодняшнему расколу, но его предупреждение не было услышано из-за риторики политической корректности.

В то же время выходец из России британский профессор Т. Шанин дал образ-сценарий России как страны третьего мира. Намереваясь стать страной первого мира из-за неудовлетворенности своим статусом страны второго мира, Россия, по его мнению, оказались в третьем мире. От третьего мира даже тогда Россию отличало образованное население, завершенная индустриализация, тысячелетняя история цивилизационного развития, великая литература и другие достижения, известные всему миру, хорошая система образования. СССР был одним из полюсов в противостоянии систем - первого и второго мира, по отношению к которым произошла идентификация третьего мира. Россия в течение трех веков осуществляла модернизацию. В ней прочно европейское начало. Отличия от Запада, инкриминируемую России в это время «третьемирскость», имел и Китай. Включение этих великих стран в разряд стран третьего мира явилось девелопментализмом худшего сорта, когда место страны в мире определяется только экономическими понятиями.

В 1996 г. К. Коукер изучил подъем и падение атлантизма, поставив диагноз «сумерки Запада».

В 2000 г. в России под ред. И.В. Бестужева-Лады появилась антология современной классической прогностики 1953-1999 гг. «Впереди XXI век», в котором были опубликованы самые знаменитые мировые прогнозы указанного времен.

В 2001 г. вышла книга «Мегатренды мирового развития» под ред. М.В. Ильина и В.Л. Иноземцева, в которой были рассмотрены тенденции, вызываемые глобализацией.

В 2002 г. консервативный американский политолог П. Бьюкенен выступил с прогнозом «смерти Запада», говоря о гибнущих американских ценностях.

В 2002 г. Ф. Фукуяма издал работу «Наше постчеловеческое будущее» о последствиях биотехнологической революции.

В 2008 г. Ф. Закария, видный американский политолог, опубликовал работу о постамериканском мире, подчеркнув, что его прогноз - не о падении США, а о подъеме остального мира.

В 2009 г. опубликована книга А.И. Уткина, В.Г. Федотовой «Будущее глазами Национального совета по разведке США: глобальные тенденции до 2025 года», обсуждающая прогнозы этой организации до 2020 г.

В 2011 г. вышла в свет книга А.И. Уткина «ХХІ век» с прогнозами будущего на этот период и анализом имеющихся прогнозов.

Обратимся к двум американским сценариям развития США, представленным к инаугурациям Президента США. В 2004 г. Национальный совет по разведке США, включающий широкое интеллектуальное сообщество, опубликовал прогноз до 2020 г. В нем Россия не занимала особого места. Доклад назывался «Контуры мирового будущего» и представлял собой сценарийтренд, комбинированный со сценарием-идеологией американского будущего. В нем утверждалось, что «линейный анализ позволит нам получить значительно видоизмененную гусеницу, но никак не бабочку - для этого нужен скачок воображения. Мы надеемся, что данный проект... позволит нам совершить такой скачок - не предсказать, каким будет мир в 2020 г. (это явно лежит за пределами наших возможностей), а тщательно подготовиться к разнообразным трудностям, которые могут ожидать нас на нашем пути» $[9,4]$. Этот вполне «политически корректный» документ отличался тем, что, указывая на ряд тенденций, подрывающих могущество и однополярность США (например, возвышение Китая и Индии), он не рассматривает мир как квазиприродный и утверждает роль США в будущей мировой политике. Сценарий-проект был прямо ориентирован на переустройство общества и предлагался реальным политическим субъектам.

Следующий доклад был подготовлен к инаугурации Б. Обамы в 2008 г. и содержал прогнозы до 2025 г. Его сценарии: 
Первый сценарий: Мир без Запада, подъем незападных стран, включая Россию. Второй сценарий: Наводнение на Манхеттене. Проблема изменения климата. Третий сценарий: БРИК подорван внутренними противоречиями. Четвертый сценарий: Политика не всегда имеет локальный характер. Рост донациональных и постнациональных образований[ 9 ].

У прогнозов будущего есть еще черта мегаломании, неограниченности сроков прогноза, попыток усложнять простые проблемы. В Китае, в Институте Евразии и развития при Госсовете, рассказывая об успехах и проблемах своей реформы, китайцы объясняли, как они решали сложные вопросы, способные расколоть общество. Вопросы, которые вызывали бы у нас многолетнюю дискуссию, получали у них неожиданно простые ответы: «Кто такой Мао Цзэдун?» — «Мао Цзэдун — тоже человек». «Как относиться к учению Мао Цзэдуна?» — «Всякое учение развивается, учение Мао Цзэдуна тоже». «Как относиться к распаду коммунизма в России?» - «Как к внутреннему делу России». «Как акционировать предприятия, если они плохо акционируются?» — «Подождать, пока будут акционироваться хорошо». Прошло не так много лет, но сегодня это - уже не вопросы, которые волнуют Китай. Согласие по поводу базовых ценностей в Китае, достигнутое вследствие ряда успешных реформ, позволяет упрощать сложные проблемы в интересах этого согласия. Россия - расколотая страна, испытавшая и испытывающая ценностные надломы и даже в хорошие времена мало способная к подобным компромиссам на уровне здравого смысла.

Правительство и группы независимых ученых могут дать серьезную и реалистическую оценку положения в стране. Когда ученым говорят, что они должны помочь, внести свои предложения, имеется в виду, что есть задачи, которые поставлены политиками, которые кто-то пытается решить и не может. И ученые помогут. Но такие задачи не поставлены. Поэтому сценарии будущего копятся про запас, ждут своей востребованности. Их много, но они разного типа и характеризуют разные контексты.

\section{Сценарии-тренды}

Сценарии-тренды будущего России были связаны с поиском объективных тенденций. Они были, как правило, политически нейтральны, не тяготели ни к левым, ни к правым силам, а, скорее, к центристским представлениям, имели разную степень абстрактности, применимости и ориентации на разные субъекты, не были проработаны в деталях, но намечены в своих принципах.

Сценарий-тренд глобальных ценностных изменений, связанный с технологическими инновациями В нем утверждается, что сегодня кризис ценностей имеется не только в России, но и на Западе и в мире в целом. Это обусловлено переходом Запада в постиндустриальное общество и глобализацией. Первый значительный сдвиг в технологиях — переход от аграрного общества к индустриальному - вызвал слом ценностей и формирование новых, отвечающих новому содержанию эпохи. Соглашаясь с этим сценарием в принципе, мы не можем его операционализировать, сказать, что надо делать в социальном, экономическом и политическом планах в России. Философский прогноз - это с неизбежностью мысленное творение истории, которое не является технологическим проектом, но дает представление о стратегии, в частности стратегии отказа от экономоцентризма и большего внимания к проблемам морали, ценностей, культуры, политической культуры.

Сценарий-тренд национальной модели модернизации, осуществляющей развитие на основе собственной идентичности.

Тренд, объективно обусловленный, реализуемый в Китае, Индии, Бразилии, но «грубо сколоченный» в России прямым соединением в сценарии-проекте и сценарии-идеологии из традиционных ценностей и обычаев с высокими технологиями. 


\begin{tabular}{|c|c|c|c|c|}
\hline HTP & Длительность & Основное содержание & Научная революция & $\begin{array}{c}\text { Индустриальная } \\
\text { революция }\end{array}$ \\
\hline $1-\mathrm{ag}$ & 16-17-ый века & $\begin{array}{l}\text { Рождение современной } \\
\text { физики }\end{array}$ & 1-ая научная революция & - \\
\hline 2-aя & $\begin{array}{l}\text { С середины до } \\
\text { конца 18-ого } \\
\text { века }\end{array}$ & $\begin{array}{l}\text { Революция, возникшая в } \\
\text { связи с открытием } \\
\text { парового двигателя и } \\
\text { использованием пара в } \\
\text { технике }\end{array}$ & $\begin{array}{l}\text { 1-ая технологическая } \\
\text { Революция }\end{array}$ & 1-aя \\
\hline $3-я$ & $\begin{array}{l}\text { С середины до } \\
\text { конца 19-ого } \\
\text { века }\end{array}$ & $\begin{array}{l}\text { Революция, принесенная } \\
\text { электричеством и } \\
\text { транспортом }\end{array}$ & $\begin{array}{l}\text { 2-ая технологическая } \\
\text { революция }\end{array}$ & 2-ая \\
\hline 4-aя & $\begin{array}{l}\text { Первая половина } \\
\text { 20-го века }\end{array}$ & $\begin{array}{l}\text { Теория относительности, } \\
\text { квантовая теория и др. }\end{array}$ & $\begin{array}{l}\text { 2-ая научная } \\
\text { Революция }\end{array}$ & - \\
\hline \multirow[t]{2}{*}{$5-$ aя } & $\begin{array}{l}\text { Середина 20-го } \\
\text { века }\end{array}$ & Электроника и автоматика & $\begin{array}{l}\text { 3-я технологическая } \\
\text { революция }\end{array}$ & $3-9$ \\
\hline & $\begin{array}{l}\text { С середины до } \\
\text { конца 20-ого } \\
\text { века }\end{array}$ & $\begin{array}{l}\text { Информационные } \\
\text { технологии и сети }\end{array}$ & $\begin{array}{l}\text { 4-я технологическая } \\
\text { Революция }\end{array}$ & 4-ая \\
\hline 6-aя & $\begin{array}{l}\text { Середина 21-ого } \\
\text { века }\end{array}$ & $\begin{array}{l}\text { Революция, приносимая } \\
\text { новой биологией, новой } \\
\text { интеграцией жизни с } \\
\text { помощью биологии, } \\
\text { биотехнологиями }\end{array}$ & $\begin{array}{l}\text { 3-я научная революция } \\
\text { 5-ая технологическая } \\
\text { революция }\end{array}$ & 5-ая \\
\hline 7-ая & $\begin{array}{l}\text { Середина 21-ого } \\
\text { века }\end{array}$ & $\begin{array}{l}\text { Революция, приносимая } \\
\text { новыми идеями физики в } \\
\text { понимании пространства- } \\
\text { времени (многомерность), } \\
\text { новой энергией и новыми } \\
\text { видами транспорта. }\end{array}$ & $\begin{array}{l}\text { 4-ая научная революция } \\
\text { 6-ая технологическая } \\
\text { Революция }\end{array}$ & 6-ая \\
\hline
\end{tabular}

Таблица. Соотношение между научно-техническими революциями и революциями, начиная с 16 века [1, с. $12-16]$

Сиенарий-тренд технологических изменений. В течение одного месяца я встречаю у разных исследователей (В. Лепского, С. Глазьева и Ч. Хэ) одну и ту же схему смены технологических циклов, совпадающую вплоть до пятого, но начинающую различаться на шестом и особенно седьмом (введенным проф. Хэ). Изложу эту концепцию в наиболее полном виде, приводя таблицу этого китайского коллеги.

Работая в парадигме естествознания в том смысле, чтобы создать специальную науку модернизации, профессор Хэ рассказывал нам о тех не вошедших в схему опасностях, которые влекут за собой биотехнологии. Будучи ученым-биологом, профессор Хэ работал в китайском консульстве в США и отвечал там за закупки передовой американской техники. Меня лично просто 
потрясло, что он начал заниматься китайской модернизацией, считая, что его работа по закупке техники требует теоретических знаний и ценностных ориентаций, которые бы направили на верные решения в конкретной сфере. Заметим, что Китай сегодня закупает в США в 500 раз больше передовой техники, чем это было совсем недавно. Сегодня профессор Хэ выпустил на Западе огромную книгу под названием «Наука модернизации. Принципы и методы национального продвижения» [3]. Что касается седьмого предложенного им цикла, он ужасал и восхищал не введением многомерного пространства-времени и живущих в нем необычных людей, таких, как сидящие у компьютеров группы, smartbionicbodies и прочие совсем не похожие на нас люди, легко избавляемые от смерти пересаживанием в другие тела. На вопрос о том, как сохранить человечество, профессор Хэ, будучи подлинным технократом, ответил, что это - роль социальных наук. Но неумолимость научно-технологических детерминант, прослеживаемая в истории и нависшая над будущим, превращает модернизацию в бессубъектный технологическидетерминированный процесс, с которым мы могли справляться до определенных пор и можем справиться или не справиться в будущем. В Центре модернизации в Шанхае работают как специалисты по предприятиям, так и историки, и философы. Первые очень реалистичны, хотя призывают и к сверхзадаче учета повседневного сознания. Вторые очень идеалистичны и говорят в марксистских терминах о всесторонне развитом, творческом и гармоничном человеке. Эта привлекательная пафосом риторика вряд ли отвечает забегающему вперед миру технологий, и творчество не тождественно благим целям. У него демиургическая природа, а, когда мир демиургически творится техникой, тоже творчески, альтернатива в творчестве с необозначенной направленностью явно хромает.

С. Глазьев, выступая на посвященной Евразес, организованной Институтом экономических стратегий РАН и проходившей в ИФ РАН конференции, полагал, что экономические союзы наиболее адекватны требованиям гуманизации новых технологических и экономических циклов. В. Лепский опубликовал немало книг и статей, где он настаивает, что переходу к новым технологическим циклам должны сопутствовать или предшествовать социогуманитарные революции, без чего скачок в неведомое станет опасным [4]. Это приближает к некоторым идеям социально-проективного подхода, способного представить возможности технологии, которые, кстати, не совсем представимы за пределами пятого цикла, и создать соответствующие им возможности человеческих сред. Проблему человека выдвигают на передний план такие ученые, как В. Веряскина, И. Сиземская. Экологический вызов социоприродному универсуму рассматривает Ю. Олейников. Поскольку сектор социальной философии избрал в качестве плановой многолетней темы «Истории и теории модернизаций», замечу, что актуальной задачей становится экспликация типа человека, возникающего в ходе научно-технических революций и предложения о социально-гуманитарном и гуманитарном предшествовании технологическим революциям сегодня, о границах модернизации в экологии и человеке, об опасности бессубъектной модернизации.

Без сценария. Прежде это была манипуляция как субститут демократии, сегодня бюрократические инновации во всех сферах жизни. Мы видим, что многие сценарии, казавшиеся очевидными, не осуществились. В прогнозировании появились альтернативы, не позволяющие видеть только одну сторону. Сегодня каждый день мы имеем дело с глобализацией-локализацией, постиндустриа-лизацией-деиндустриализацией - реиндустриализацией, мульти-культурализмом монокультурализмом, угрозой нехватки ресурсов, изменения климата, непредсказуемых последствий нашей деятельности. 


\section{Библиографический список:}

1. Глазьев С.Ю. Закономерности долгосрочного технико-экономического развития // Нанотехнологии как ключевой фактор нового технологического уклада в экономике / Под ред. С.Ю. Глазьева и В.В. Харитонова. М.: Тровант. 2009. С. 9-26. 12-13

2. Лепский В.Е.Рефлексивно-активные среды инновации. М.: КОГИТО-Центр. 2010. 255 с.

3. Уткин А.И., Федотова В.Г. Будущее глазами национального совета по разведке США: Изменившийся мир. М.: Институт академической стратегий, Международная академия будущего. 2009. 351с.

4. Федотова В.Г. Хорошее общество. М.: Прогресс-Традиция. 2005. 543 с.

5. Таблица заимствована у российского автора исследователя В. Гулько, который тоже не является ее автором, но продолжена выделением шестого и седьмого цикла, являющегося гипотезой профессора Хэ. См.: ChuanciHe. S\&T Revolution and World Modernization // Modernization Science. Newsletter. Vol.1, № 8, December 2011. P. 4

6. Chuanqi He. Modernization Science. The Principles and Methods of National Advancement. Heidelberg, Dordrechts, L., N. Y.: Kluger. 2012. 648 p.

8. Global Trends 2025: A Transformed World. The National Intelligence Council's 2025 Project. Wash., 2008.

9. Mapping the Global Future: Report of the National Intelligence Council's 2020 Project. Wash., 2004.

\section{Fedotova, V. P. Global Scenario Types and the Line of Vector for Russia}

The increasing nonlinearity of social change, so peculiar to the turn of the XXI century, is drastically transforming the mechanisms of prognosticating development scenarios. Extrapolating futurological models give way to nonlinear probabilistic forecasts - "projects", in which determination of development prospects is impossible without taking into account social-engineering enterprise. The proposed typology of futurological scenarios reveals the complexity of objective vision of the possible future in the focus of the sweeping global development.

Key words: prognosticating, futurological development scenarios, scenarios-projects, scenariostrends, scenarios-ideologies, scenarios-images. 